\title{
Status Quo Effects in Fairness Games: Reciprocal Responses to Acts of Commission vs. Acts of Omission
}

\author{
James C. Cox \\ Experimental Economics Center and Department of Economics \\ Andrew Young School of Policy Studies \\ Georgia State University \\ Maroš Servátka \\ New Zealand Experimental Economics Laboratory \\ Department of Economics and Finance \\ University of Canterbury \\ Radovan Vadovič \\ Centro de Investigación Económica \\ Instituto Tecnológico Autónomo de México
}

February 29, 2012

\begin{abstract}
Both the law and culture make a central distinction between acts of commission that overturn the status quo and acts of omission that uphold it. In everyday life acts of commission often elicit stronger reciprocal responses than do acts of omission. In this paper we compare reciprocal responses to both types of acts and ask whether behavior of subjects in two experiments is consistent with existing theory. The design of the experiments focuses on the axioms of revealed altruism theory (Cox, Friedman, and Sadiraj, 2008) that make it observationally distinct from other theories, Axiom R (for reciprocity) and Axiom $S$ (for status quo). We find support for this theory in both experiments.
\end{abstract}




\section{Introduction}

Does it make a difference whether an event results from action or inaction by another person? In this paper we compare reciprocal responses to acts of commission that actively impose harm or kindness and acts of omission, representing failure to prevent harm or to act kindly. We use two experiments to test a hypothesis (implied by Axioms $\mathrm{R}$ and $\mathrm{S}$ in Cox, Friedman and Sadiraj, 2008) that acts of commission induce stronger reciprocal responses than comparable acts of omission.

There are many everyday examples where acts of commission yield stronger reciprocal responses than do acts of omission. For example, a waiter may be rewarded with an extremely large tip for going out of his way to serve a customer but might still be tipped according to the norm even if he failed to fulfill an extraordinary request. A mobster may retaliate with a bloody vengeance because someone intentionally hurt his family member but might not hurt a bystander who did not prevent the harm. Legal consequences may vary from probation to capital punishment to damages in millions of dollars depending on level of intent inferred from acts of commission or omission.

Acts of commission vs. acts of omission have important implications for legal decisions because they are often used to infer defendants' intentions. In criminal law, actus reus (the act of committing a crime) and mens rea (the state of mind) are crucial when deciding whether a person is guilty of a specific crime, some other crime, or no crime. The party responsible for the death of a human being can be convicted of criminally negligent homicide if the death was caused (beyond reasonable doubt) by a form of gross negligence. For example, gross negligence includes the failure to stop and render aid in a hit-and-run accident, which is an act of omission. A murder conviction, however, requires that the person had (beyond reasonable doubt) an intention to kill, which (in the vast majority of known murder cases) is inferred from acts of commission. ${ }^{1}$

\footnotetext{
${ }^{1}$ Most, if not all, everyday life examples suffer from the fact that acts of commission differ from acts of omission in some other aspect(s) of behavior, usually the amount of effort necessary to take an action. Such confounds can cloud the intuition and make it hard to unambiguously attribute the causality solely to the difference between commission and omission. In a laboratory we are able to hold other aspects of the environment constant which allows us to control for such confounds. This makes a laboratory experiment an indispensable tool for studying this particular research question.
} 
In tort law, compensatory damages are awarded for ordinary negligence due to the harmful consequences of an act of omission. However, in a particularly egregious case where the tort was reasonably foreseeable and, despite this, the harmful act was committed then punitive damages may be awarded. ${ }^{2,3}$

The distinction between acts of commission and acts of omission has been explored in depth by philosophers whose main focus was on morality of the action. Some philosophers conclude that the distinction between the two types of acts is often morally irrelevant (Bennett 1966, 1981, 1983; Singer, 1979; Hare, 1981) while others argue for the relevance of the distinction (Kagan, 1988; Kamm, 1986; Steinbock, 1980). ${ }^{4}$ Psychologists point out that some of the cases studied by philosophers often differ in other aspects than just acts of commission vs. omission and that philosophers themselves are often subject to psychological biases, and therefore it is reasonable to assume that there is no difference in morality between the two types of acts. Under this assumption they study causes of the omission bias (i.e., when subjects judge harmful commissions as

\footnotetext{
2 "To support award of punitive damages, act which constitutes the cause of action must be activated by or accompanied with some evil intent, or must be the result of such gross negligence - such disregard of another's rights - as is deemed equivalent to such intent." (Newport v. USAA 11 P.3d 190 Okla., 2000, July 18, 2000). See also Feinberg (1984) on further discussion on how the law distinguishes between acts of commission and acts of omission.

${ }^{3}$ An interesting example of awarding punitive damages is the tobacco litigation. In Florida, the information that the tobacco industry knew that cigarettes were harmful, nicotine was addictive, and there were risks from second-hand smoking, obtained in the mid-nineties by whistleblowers Merrell Williams and Jeffrey Wigand, was used for the first time in a jury trial. It was the first time that an individual won a lawsuit for lung cancer. In 2000, a Florida jury awarded the biggest punitive damages in US history at the time, $\$ 144.8$ billion. This lawsuit explored the pattern of lies and bogus claims produced by tobacco companies while knowing that the use of their product was detrimental to consumers' health and could cause death. The jury foreman said: "This verdict wasn't about the state of the tobacco industry today. It was about 50 years of fraud, misrepresentation, and lying to the American public." (Tobacco News, www.tobacconews.org) According to the jury verdict, the amount of punitive damages was not as important as the strong message of the large judgment and that Big Tobacco must - and will - be held accountable (Schlueter, 2005, p. 573-577).

${ }^{4}$ A representative of this debate is the famous ethics thought experiment involving a trolley: "A trolley is running out of control down a track. In its path are five people who have been tied to the track by a mad philosopher. Fortunately, you could flip a switch, which will lead the trolley down a different track to safety. Unfortunately, there is a single person tied to that track. Should you flip the switch or do nothing?" (Foot, 1978). See also Thomson 1985; Unger, 1996; Kamm, 1989, Greene, 2007, Moll and de OliveiraSouza, 2007.
} 
worse than the corresponding omissions), such as loss aversion, exaggeration effect, overgeneralization, and commissions being linked to causality judgments. ${ }^{5}$ The omission bias is closely related to the bias toward the status quo, "doing nothing or maintaining one's current or previous decision" that Samuelson and Zeckhauser (1988) found in risky as well as in riskless choices and which has also been found in reactions to outcomes (Kahneman and Tversky, 1982; Viscusi, Magat, and Huber, 1987; Knetsch, Thaler, and Kahneman, 1988; Ritov and Baron, 1992; Baron and Ritov, 1994). The current paper digs deeper in exploring the impact of the status quo, which distinguishes acts of commission from acts of omission, by focusing on its relevance for the strength of reciprocal responses.

The central question of our study can be stated as: Do acts of commission that overturn the status quo generate a stronger reciprocal response than acts of omission which uphold it? Consider the following two stylized thought experiments.

Scenario 1: Your initial wealth is $\$ 100 \mathrm{~K}$ and John's initial wealth is $\$ 100 \mathrm{~K}$.

A. Suppose John had an opportunity to give you $\$ 10 \mathrm{~K}$ but did not do so. Would you want to punish him?

B. Now suppose John does give you $\$ 10 \mathrm{~K}$. Would you want to reward him?

Scenario 2: Your initial wealth is $\$ 110 \mathrm{~K}$ and John's initial wealth is $\$ 90 \mathrm{~K}$.

C. Suppose John had an opportunity to take $\$ 10 \mathrm{~K}$ from you but did not do so. Would you want to reward him?

D. Now suppose that John does take $\$ 10 \mathrm{~K}$ from you. Would you want to punish him?

The two scenarios highlight the relationship between reciprocity and status quo. In Scenario 1, the status quo is that you did not own the $\$ 10 \mathrm{~K}$ and John: (i) did not give it to you (an act of omission); or (ii) did give it to you (an act of commission). In Scenario

\footnotetext{
${ }^{5}$ For a further discussion see Spranca, Minsk, and Baron (1991) who also present an interesting psychology experiment showing that subjects often rate harmful omissions as less bad than harmful commissions. Subjects' ratings are associated with judgments that omissions do not cause outcomes.
} 
2 , the status quo is that you did own the $\$ 10 \mathrm{~K}$ and John: (i) did not take it from you (an act of omission); or (ii) did take it from you (an act of commission).

The importance of status quo and acts of commission or omission are particularly compelling when comparing scenario 1.A with 2.D and 1.B with 2.C. In both scenarios 1.A and 2.D, your final payoff is $\$ 100 \mathrm{~K}$ and John's final payoff is also $\$ 100 \mathrm{~K}$. But in scenario 2.D John actively takes $\$ 10 \mathrm{~K}$ from you while in scenario 1 .A he passively makes no change in payoffs. In both scenarios 1.B and 2.C your final payoff is $\$ 110 \mathrm{~K}$ and John's is $\$ 90 \mathrm{~K}$. But in scenario 1.B John actively gives you $\$ 10 \mathrm{~K}$ while in scenario 2.C he passively makes no change.

Distributional preference theories do not discriminate between acts of commission, acts of omission, and no opportunity to act. These distinctions, however, are central to understanding reciprocal preferences. Cox (2004) focused on the importance of the distinction between acts of commission vs. no opportunity to act in experimental designs for studying trust and reciprocity. Cox, Friedman, and Sadiraj (2008) developed a theory of reciprocity that focuses on all three types of acts. Their Axiom S captures the intuition behind the distinction between Scenarios 1 and 2: an act of commission implies stronger reciprocal response than an act of omission. (We give a detailed description of Axiom $\mathrm{S}$ in a later section.)

Little empirical work, however, has focused on the effects of acts of commission vs. acts of omission defined relative to the status quo. In this paper we report direct evidence on this topic. We present two experiments specifically designed to test the empirical validity of Axiom $\mathrm{S}$ and to provide further insights about experimental protocols under which support for Axiom S can be detected. We develop a procedure - a combination of initial endowments and appropriate labeling of actions that frames the game in terms of monetary transfers - that makes the status quo salient in a laboratory setting and that puts active behavior in stark contrast with inaction.

In our treatments we compare the behavior in two games that vary in terms of their induced status quo, i.e. with respect to their initial endowments, and the resulting framing of feasible actions as acts of commission or acts of omission. Importantly, we 
keep the terminal payoffs in both games the same, which gives us a clean test of Axiom $\mathrm{S}$, a component of revealed altruism theory.

\section{Status Quo Treatments}

Our experimental design includes two treatments. In treatment $T_{15,5}$ the first mover, Player A has an endowment of 15 dollars and the second mover, Player B has an endowment of 5 dollars. Player A has two possible moves: she can choose "Uphold $(15,5)$, , that is make no change in the endowments, or she can choose to "Give 5 " out of her 15 dollar endowment to Player B. If Player A chooses "Uphold $(15,5)$ " then Player B has two possible choices: he can choose "No Decrease" or he can choose to "Decrease by 6 " the endowment of Player A at a cost to himself of 2 dollars. These possible choices in treatment $T_{15,5}$, and the money payoffs they yield, are shown on the left side (or leg) of Figure 1a. The top number at a terminal node of the game tree is the dollar payoff to Player A and the bottom number is the dollar payoff to Player B. If Player A decides to "Give 5" to Player B then Player B has two possible choices: she can choose "No Increase" or she can choose to "Increase by 2" the endowment of Player A at a cost to herself of 1 dollar. These possible choices in treatment $T_{15,5}$, and the money payoffs they yield, are shown on the right side (or leg) of Figure 1a.

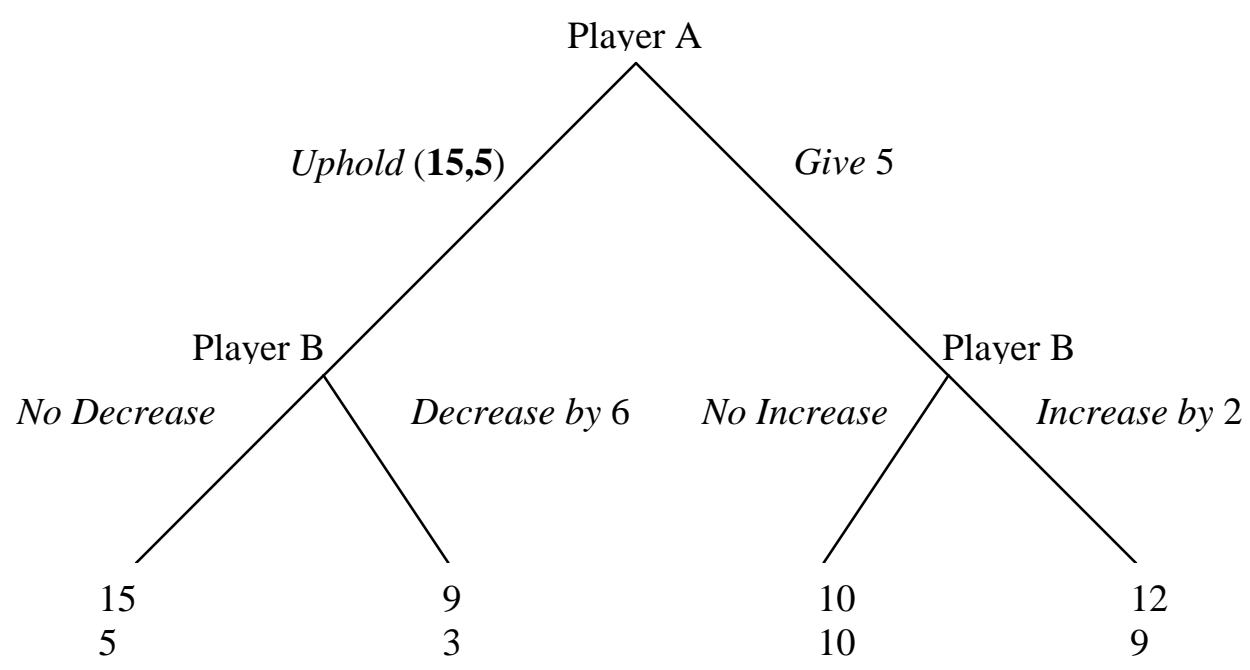

Figure 1a. Treatment $T_{15,5}$ 
In treatment $T_{10,10}$ both Player A and Player B have 10 dollar endowments. Player A has two possible moves: she can choose to "Take 5" from Player B or choose "Uphold $(10,10)$ ", that is make no change in the endowments. If Player A chooses "Take 5" then Player B has two possible choices: he can choose "No Decrease" in the modified endowments or he can choose (to) "Decrease by 6" the modified endowment of Player A at a cost to himself of 2 dollars. These possible choices in treatment $T_{10,10}$, and the money payoffs they yield, are shown on the left side (or leg) of Figure 1b. If Player A chooses "Uphold $(10,10)$ " then Player B has two possible choices: she can choose "No Increase" or she can choose (to) "Increase by 2" the endowment of Player A at a cost to herself of 1 dollar. These possible choices in treatment $T_{10,10}$, and the money payoffs they yield, are shown on the right side (or leg) of Figure $1 \mathrm{~b}$.

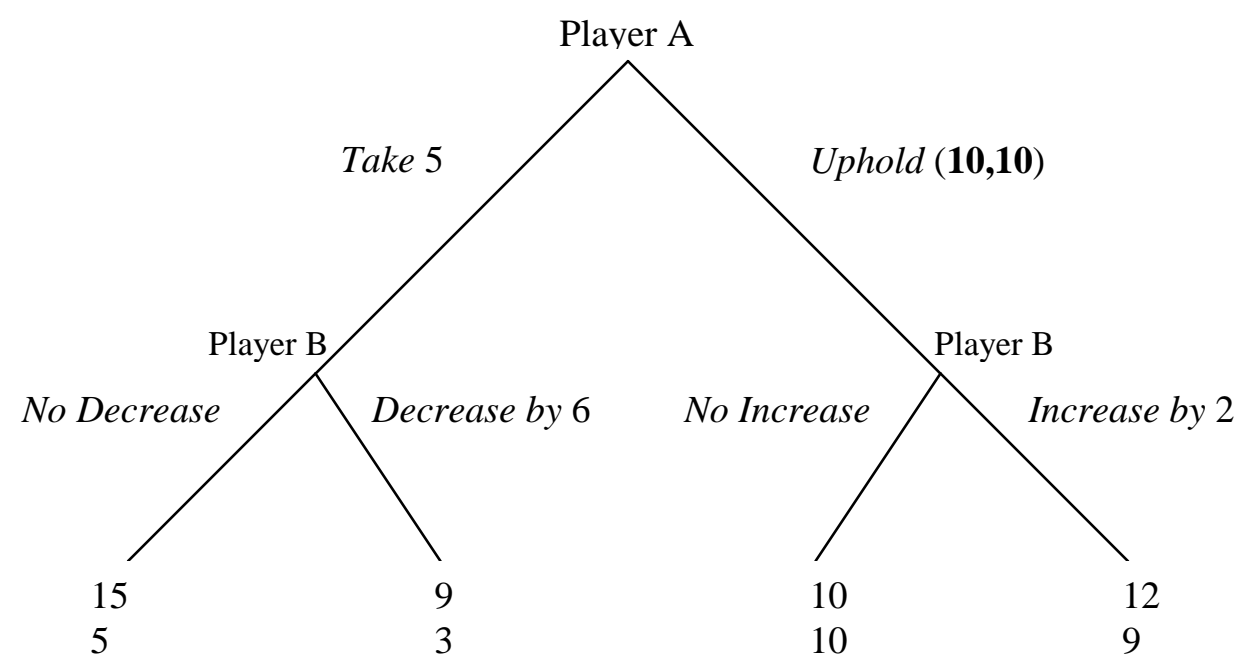

Figure 1b. Treatment $T_{10,10}$

Figure 1a and Figure 1b have the same ordered pairs of money payoffs at their corresponding terminal nodes. However, in order to reach a terminal node with given money payoffs $(x, y)$, Player A and Player B must choose a different sequence of actions in treatment $T_{15,5}$ than in treatment $T_{10,10}$. Whether or not it is only the payoffs at the terminal nodes that are predicted to determine agent choices or, alternatively, both payoffs and actions, depends on the theoretical model. In a theory of reciprocity, such as 
Cox, Friedman, and Sadiraj (2008), a first mover's more or less generous action can make a second mover more or less altruistic.

\section{Implications of Alternative Theoretical Models for Play in the Two Treatments}

\subsection{The Two Status Quo Treatments Are Equivalent for Most Theories}

The theoretical predictions of the special case version of game theory for selfregarding (or "economic man") preferences are obvious. Given that each player only cares about his own money payoff, Player A will choose Uphold $(15,5)$ and Player B will choose No Decrease in treatment $T_{15,5}$, which results in the ordered pair of (Player A, Player B) payoffs of $(15,5)$. In treatment $T_{10,10}$, Player A will choose Take 5 and Player B will choose No Decrease, which results in the ordered pair of (Player A, Player B) payoffs of (15,5). For this special case interpretation, treatment $T_{15,5}$ and treatment $T_{10,10}$ involve the same game; the only difference between the games is a theoreticallyirrelevant difference in how the game is framed.

Models of (unconditional) distributional preferences such as Fehr and Schmidt (1999), Bolton and Ockenfels (2000), Cox and Sadiraj (2007), and the text model in Charness and Rabin (2002), as well as belief-dependent reciprocity models by Dufwenberg and Kirchsteiger (2004) and Falk and Fischbacher (2006), do not imply that all play will end at the $(15,5)$ node in the two treatments because they model otherregarding or social preferences which are not necessarily the same as economic man preferences over ordered pairs of money payoffs. Furthermore, the different distributional

preference models may have different implications about which of the four possible ordered pairs of payoffs (at the four terminal nodes) will be preferred by Player B. But all of these models represent social preferences in which an agent's utility of alternative allocations of material payoffs depends only on the (absolute and relative) amounts of the payoffs themselves or on a priori beliefs, not on the agents' acts of commission or omission that may be necessary to generate the allocations in any particular game. Therefore, all of these models imply that Player B will make the same choice between two final payoff allocations, $(a, b)$ or $(c, d)$, in treatment $T_{15,5}$ as in treatment $T_{10,10}$. 
According to these models, the only difference between treatment $T_{15,5}$ and treatment $T_{10,10}$ is a difference in the framing of the (same) game that is theoretically irrelevant to prediction of play of the game. $^{6}$

\subsection{The Two Status Quo Treatments are Not Equivalent for Revealed Altruism Theory}

Revealed altruism theory (Cox, Friedman, and Sadiraj, 2008) or its special parametric form (Cox, Friedman, and Gjerstad, 2007) has previously predicted outcomes quite successfully in several different types of experiments including the dictator game (with and without earned endowments), ultimatum game, ultimatum mini-game, investment game, moonlighting game, Stackelberg duopoly game, Stackelberg minigame, and carrot and stick games. The theory has also successfully predicted behavior in paired public good and common pool games (Cox and Hall, 2010).

Revealed altruism theory (Cox, Friedman, and Sadiraj, 2008) predicts that play will differ between the $T_{15,5}$ and $T_{10,10}$ treatments in the experiments reported here. Elements of that theory include a partial ordering of opportunity sets, a partial ordering of preferences, and two axioms about reciprocity. The partial ordering of opportunity sets is as follows. Let $m$ denote Player B's ("my") money payoff and let $y$ denote Player A's ("your") money payoff. Let $m_{H}^{*}$ denote my maximum money payoff in opportunity set $H$ and let $y_{H}^{*}$ denote your maximum money payoff in opportunity set $H{ }^{7}$ Opportunity set $G$ is "more generous than" opportunity set $F$ if: (a) $m_{G}^{*}-m_{F}^{*} \geq 0$ and (b) $m_{G}^{*}-m_{F}^{*} \geq y_{G}^{*}-y_{F}^{*}$. In that case, one writes $G$ MGT $F$. Part (a) in the definition of the MGT partial ordering is the statement that opportunity set $G$ is more generous (to me) than is opportunity set $F$ if my largest possible payoff in $G$ is not less than my largest payoff in $F$. The role of part (b) in the MGT definition is to discriminate between choices

\footnotetext{
${ }^{6}$ It has been argued that cumulative prospect theory (with loss aversion) implies that the $\mathrm{T}_{15,5}$ and $\mathrm{T}_{10,10}$ games are not isomorphic. This argument is critically examined in Appendix D.

7 More formally, $m_{H}^{*}=\sup \{m: \exists y \geq 0$ s.t. $(m, y) \in H\}$ and $y_{H}^{*}=\sup \{y: \exists m \geq 0$ s.t. $(m, y) \in H\}$.
} 
by you that are clearly intended to benefit me and other choices that might reflect "selfserving generosity" in which you mainly intend to benefit yourself: $y_{G}^{*}-y_{F}^{*}>m_{G}^{*}-m_{F}^{*}$.

For example, our treatments $T_{15,5}$ and $T_{10,10}$ include the same two opportunity sets for Player B. Let $F=\{(15,5),(9,3)\}$ denote Player B's opportunity set if Player A moves "left" and $G=\{(10,10),(12,9)\}$ denote Player B's opportunity set if Player A moves "right" in either treatment. Note that, for these sets, $G$ MGT $F$ for Player B.

The partial ordering of preferences is as follows. My willingness to pay (amounts of my material payoff, $m$ ) to increase your material payoff, $y$ can depend on the absolute and relative amounts of our payoffs. In the case where marginal utilities are welldefined, my willingness to pay is given by the ratio of marginal utilities: $W T P(m, y)=u_{y}(m, y) / u_{m}(m, y)$. Two different preference orderings, $A$ and $B$, over allocations of material payoffs might represent the preferences of two different agents or the preferences of the same agent in two different situations. For a given domain $D$, preference ordering $A$ is "more altruistic than" preference ordering $B$ if $W_{T P}(m, y) \geq \operatorname{WTP}_{B}(m, y)$ for all $(m, y) \in D$. In that case, we write $A$ MAT $B$.

Revealed altruism theory states that an individual's preferences can become more or less altruistic depending on the actions of another agent. Reciprocity, denoted as Axiom R, states that if a first mover provides a more (resp. less) generous opportunity set to the second mover then the second mover's preferences will become more (resp. less) altruistic towards the first mover. ${ }^{8}$ Axiom R implies that Player B's preferences will be more altruistic if Player A moves "right" than if she moves "left" in either treatment $T_{15,5}$ or treatment $T_{10,10}$.

Although the collection of opportunity sets that Player A can offer Player B are identical in treatments $T_{15,5}$ and $T_{10,10}$, the status quo set that corresponds to the endowments is different. The more generous opportunity set in treatment $T_{10,10}$ is selected by an act of commission by Player A (giving $\$ 5$ to Player $\mathrm{B}$ ). The more generous opportunity set in treatment $T_{15,5}$ is selected by an act of omission by Player A (making

\footnotetext{
${ }^{8}$ See Cox, Friedman and Sadiraj, 2008, p. 40 for a formal definition of Axiom R.
} 
no change). Similarly, the less generous opportunity set in the $T_{10,10}$ treatment is selected by an act of commission while the less generous opportunity set in the $T_{15,5}$ treatment is selected by an act of omission.

Axiom $\mathrm{S}$ is the element of revealed altruism theory that implies that treatments $T_{15,5}$ and $T_{10,10}$ are not isomorphic. This axiom distinguishes between acts of commission, which overturn the status quo, and acts of omission which uphold the status quo. Axiom $\mathrm{S}$ says that the effect of Axiom $\mathrm{R}$ is stronger when a generous (or ungenerous) act overturns the status quo than when the same act merely upholds the status quo. Axiom $S$ states that if the decision made by a first mover overturns the status quo then the reciprocal response, for individuals with preferences consistent with Axiom $R$, will be stronger than when the status quo is upheld. ${ }^{9}$

A Player B with preferences consistent with Axioms R and S will care about how the opportunity set actually chosen by Player A compares to the other opportunity sets Player A could have chosen and also how the chosen set compares to the status quo opportunity set. The theory predicts that a Player B will respond more altruistically towards a Player A who overturns the status quo in treatment $T_{15,5}$ by choosing Give 5 than to a Player $\mathrm{A}$ in treatment $T_{10,10}$ who chooses Uphold $(10,10)$, even though these actions provide Player B with the same opportunity set. Similarly, a Player B will respond less altruistically to a Player A who overturns the status quo in treatment $T_{10,10}$ by choosing Take 5 than to a Player A who chooses Uphold $(15,5)$ in treatment $T_{15,5}$ even though these actions provide Player B with the same opportunity set.

The theoretical models reviewed in the preceding discussion provide testable hypotheses. The null hypothesis is implied by economic man theory and all unconditional distributional preference theories. The alternative hypothesis is implied by revealed altruism theory.

\footnotetext{
${ }^{9}$ See Cox, Friedman, and Sadiraj, 2008, p. 41 for a formal definition of Axiom S.
} 
$H_{o}$ : The distribution of play across the four terminal nodes is the same in treatments $T_{15,5}$ and $T_{10,10}$.

$H_{a}:$ Frequency of observation of nodes with payoffs $(15,5)$ and $(12,9)$ is greater in treatment $T_{15,5}$ than in treatment $T_{10,10}$.

Revealed altruism theory includes self-regarding (or economic man) preferences as well as other-regarding preferences, and it includes non-reciprocal preferences as well as reciprocal preferences, because the partial orderings and statements of Axioms R and S all involve weak relations ("greater than or equal to" or "preferred or indifferent to"). This implies that there are two ways in which data can be used to test the above hypothesis. The most straightforward way to test the hypothesis is to use data for all Players B in the experiment. A more nuanced use of the data reflects finer points in the structure of revealed altruism theory in that "Axiom S says that the effect of Axiom R is stronger ..." This approach uses data to test the predictions of Axiom S only for subjects who have revealed consistency with the strict-preference version of Axiom R, that is, subjects whose choices in the experiment reveal that they are (positively or negatively) reciprocal. Data for other subjects, whose choices in the experiment are consistent with both self-regarding preferences and weakly reciprocal preferences, are not used in this more nuanced test of Axiom S. Tests based on both approaches are reported below.

\section{Two Experiments}

The key to experimental testing of Axiom $\mathrm{S}$ in the laboratory is a successful implementation of the status quo. Out in the field the status quo arises naturally. In a laboratory setting, however, subjects encounter stylized decision problems in which they often lack clear ex-ante expectations. In our experiments three different design features are used to induce status quo:

(i) Initial endowments: subjects start off playing the game with initial money balances of $\$ 15$ or $\$ 5$ in treatments $T_{15,5}$ and $\$ 10$ each in treatments $T_{10,10}$. Feasible actions are possible changes in these money balances. 
(ii) Labeling of actions: we frame actions that do not cause any change in payoffs as "no change in payoffs" and actions that lead to changes in payoffs as "give/take x" or "increase/decrease by y".

(iii) Entitlements: in Experiment 1 we strengthen subjects' entitlements to their initial endowments relative to Experiment 2 by making them earn the money in the Day 1 laborious task. In Experiment 2 the initial endowments are assigned randomly.

The first two design features complement one another and provide a natural way of establishing the status quo. By (i) and (ii) the status quo is set by the initial money balances that are being changed or preserved by Player A via feasible actions. Feature (iii), however, deserves a few more comments. In Experiment 1 we opted to have the subjects earn their endowments in order to induce stronger property rights because this may be necessary for the labeling of actions (as "give" or "take" and "decrease" or "increase") to be credible. It is important that subjects perceive their endowments as actually being their own property, not "house money." The so-called "house money effect" has been documented to encourage risk taking (Battalio, Kagel, and Jiranyakul, 1990; Thaler, 1990; Thaler and Johnson, 1990; Arkes, Joyner, Pezzo, Nash, SiegelJacobs, and Stone, 1994; Keasey and Moon, 1996). Clark (2002) finds no effect of house money in the voluntary contributions mechanism public goods game using unconditional nonparametric methods. Harrison (2007), however, shows that the same data display a significant effect when analyzing responses at the individual level and accounting for the error structure of the panel data.

Several previous studies have found a notable effect of earned (rather than randomly assigned) endowments on subsequent behavior (e.g., Hoffman, McCabe, Shachat, and Smith, 1994; Rutström and Williams, 2000; Cherry, Frykblom, and Shogren, 2002; Gächter and Riedl, 2005). Cox and Hall (2010) tested robustness of the Cox, Ostrom, and Walker et al. (2009) empirical observation that the behavior of second movers does not differ between common-property and private-property trust games that include a rich strategy space for both players. Cox and Hall had their subjects earn their endowments in a real effort task prior to playing a common-property or private-property 
trust game and found the behavior of their second movers to be consistent with Axiom S, which has different predictions in the two games.

We conducted six two-day sessions (Experiment 1) and four one-day sessions (Experiment 2) in the New Zealand Experimental Economics Laboratory (NZEEL) at the University of Canterbury. A total of 274 undergraduate subjects participated in the study. Most of the students had never previously participated in an economics experiment. On average, a two-day session lasted about 120 minutes including the initial instruction period and payment of subjects. A one-day session lasted about 60 minutes. The experimental earnings, denoted in \$, were converted into cash at the 3 to 4 exchange rate: \$3 (or 3 lab \$) equals 4 New Zealand dollars, henceforth NZD. In Experiment 1 subject payments included a 10 NZD show up fee (i.e., 5 NZD for each of the two days), all paid at the end of the Day 2 session. In Experiment 2 the show up fee was 5 NZD. ${ }^{10}$

\subsection{Experiment 1: Earned Endowments}

The subjects were recruited for a two-day experiment. On Day 1 of the experiment each participant was asked to answer the same set of 40 math questions, selected from the GMAT test bank. The quiz score was the number of questions the subject answered correctly minus $1 / 4$ of a point for each incorrect answer. After everyone completed the computerized quiz (programmed in Visual Basic), the final scores were ranked from the highest to the lowest and ties were resolved randomly. Once the complete ranking of the participants had been determined, the participants who scored in the top $25 \%$ received an IOU certificate for $\$ 15$, those in the middle $25-75 \%$ received a $\$ 10$ certificate, and those in the bottom $25 \%$ received a $\$ 5$ certificate. These certificates provided the endowments for Day 2 participation. Subjects who earned $\$ 15$ or $\$ 5$ were invited to the same session on Day 2 while subjects who earned $\$ 10$ were all invited to a session that started at a different time on Day 2.

The two different Day 2 sessions constituted our experimental treatments EARNED $T_{15,5}$ and EARNED $T_{10,10}$ implemented in a between-subjects design. Day 2

\footnotetext{
${ }^{10}$ The adult minimum wage in New Zealand at the time of Experiment 1 was 12.75 NZD per hour (1 NZD $=0.75$ USD on the date of this experiment) and at the time of Experiment 213.00 NZD per hour ( $1 \mathrm{NZD}=$ 0.80 USD).
} 
sessions were run manually using the strategy method (Selten, 1967; Brandts and Charness, 2011). The design also included use of a double blind payoff protocol in which a subject's decisions are never linked with the subject's identity.

In treatment EARNED $T_{15,5}$ Player A started with $\$ 15$ and Player B with $\$ 5$, the amounts they earned on Day 1. The available choices were described to subjects as follows: Player A had to choose whether to give $\$ 5$ to an anonymously paired Player B or whether to make no change in payoffs. If Player A decided to give money, Player B could either make no further change in payoffs or decrease his own payoff by $\$ 1$ in order to increase player A's payoff by $\$ 2$. If Player A decided to make no change in payoffs, Player B could either make no further change in payoffs or decrease his/her own payoff by $\$ 2$ in order to decrease player A's payoff by $\$ 6$.

In treatment EARNED $T_{10,10}$ the subjects were first randomly assigned to be either Player A or Player B. Both types of players started with \$10 they earned on Day 1. Player A had to choose whether to take $\$ 5$ from an anonymously paired Player B or whether to make no change in payoffs. Player B's feasible choices were described exactly as in the above paragraph. Experiment 1 instructions are provided in Appendix B.

\subsection{Experiment 1 Results}

We first describe the data and then compare subjects' behavior in three ways: (i) for the whole game trees; (ii) for corresponding subgames; and (iii) for corresponding subgames after eliminating subjects who have not revealed reciprocal preferences.

Seventy subjects (or thirty-five pairs) participated in each of the two treatments. In treatment $T_{15,5}$, twenty-three $(=65.7 \%)$ Player As chose to Uphold $(15,5)$ while twelve Player As chose to Give 5 to their counterpart Player B. In treatment EARNED $T_{10,10}$, twelve $(=34.3 \%)$ chose to Take 5 while twenty-three chose to Uphold $(10,10)$. This difference in Player As' behavior is statistically significant ( $p=0.065$, Fisher's exact onesided test) ${ }^{11}$, suggesting that the status quo is an important consideration for the subjects.

\footnotetext{
${ }^{11}$ All subsequent $p$-values in this paper refer to Fisher's exact test.
} 
Player Bs' choices were elicited by the strategy method. Each player B thus made two choices, one for each of the two subgames. Their behavior is presented in Table 1.

Table 1: Player Bs' Behavior in Experiment 1

\begin{tabular}{|c|c|c|c|c|}
\hline & No Decrease & Decrease by 6 & No increase & Increase by 2 \\
\hline \multicolumn{5}{|c|}{ All Player Bs } \\
\hline EARNED $T_{15,5}$ & $27 / 35(77.1 \%)$ & $8 / 35(22.9 \%)$ & $19 / 35(54.3 \%)$ & $16 / 35(45.7 \%)$ \\
\hline $\begin{array}{l}\text { Axiom S } \\
\text { Prediction }\end{array}$ & - & $<$ & - & $>$ \\
\hline EARNED $T_{10,10}$ & $24 / 35(68.6 \%)$ & $11 / 35(31.4 \%)$ & $29 / 35(82.9 \%)$ & $6 / 35(17.1 \%)$ \\
\hline $\begin{array}{l}\text { Fisher's Test } \\
\text { for Strategies }\end{array}$ & \multicolumn{4}{|c|}{$0.061^{\mathrm{a}}$} \\
\hline $\begin{array}{l}\text { Fisher's Test } \\
\text { for Subgames }\end{array}$ & \multicolumn{2}{|c|}{0.296} & \multicolumn{2}{|c|}{0.01} \\
\hline \multicolumn{5}{|c|}{ Reciprocal Player Bs } \\
\hline EARNED $T_{15,5}$ & $13 / 21(61.9 \%)$ & $8 / 21(38.1 \%)$ & $5 / 21(23.8 \%)$ & $16 / 21(76.2 \%)$ \\
\hline $\begin{array}{c}\text { Axiom S } \\
\text { Prediction } \\
\end{array}$ & - & $<$ & - & $>$ \\
\hline EARNED $T_{10,10}$ & $4 / 15(26.7 \%)$ & $11 / 15(73.3 \%)$ & $9 / 15(60 \%)$ & $6 / 15(40 \%)$ \\
\hline $\begin{array}{l}\text { Fisher's Test } \\
\text { for Subgames }\end{array}$ & \multicolumn{2}{|c|}{0.039} & \multicolumn{2}{|c|}{0.032} \\
\hline
\end{tabular}

${ }^{\mathrm{a}}$ two-sided test.

Corresponding to the Uphold $(15,5)$ decision by Player A in treatment EARNED $T_{15,5}$, only eight (=22.9\%) Player Bs punished Player A by Decreasing his payoff by 6, while the remaining twenty-seven chose No decrease. Corresponding to the Give 5 decision, sixteen $(=45.7 \%)$ Player Bs rewarded Player A by choosing Increase by 2 , while the remaining nineteen chose No increase.

Corresponding to the Take 5 decision by Player A in treatment EARNED $T_{10,10}$, eleven (=31.4\%) Player Bs punished Player A by Decreasing his payoff by 6, while the remaining twenty-four chose No decrease. Corresponding to the Uphold $(10,10)$ decision 
by Player A, six (=17.1\%) Player Bs rewarded Player A by Increasing his payoff by 2, while the remaining twenty-nine chose No increase.

All models discussed in subsection 3.1 predict that the behavior of Player Bs in the two treatments will be identical, constituting our null hypothesis. However, according to Axiom R and Axiom S, Player Bs will behave differently due to the status quo effect (our alternative hypothesis). In order to test the null hypothesis on all data, we categorize subjects according to their strategies and perform Fisher's exact test. ${ }^{12}$ This test rejects the null hypothesis in favor of the alternative ( $p=0.061$, two-sided test). A tougher test of Axiom $\mathrm{S}$ would be to compare the behavior for each of the individual subgames. In particular, for the subgame on the left side of the game tree it implies that the frequency of "Decrease by 6" will be higher in treatment EARNED $T_{10,10}$ than in EARNED $T_{15,5}$. The one-sided Fisher's exact test does not detect a difference between frequencies with which the Decrease by 6 choice was selected in the two treatments $(p=0.296)$. For the subgame on the right side Axiom S implies that the frequency of Increase by 2 is higher in treatment EARNED $T_{15,5}$ than EARNED $T_{10,10}$. The one-sided Fisher's exact test detects a difference statistically significant at the $1 \%$ level $(p=0.01)$.

Finally, recall that Axiom S states that if the decision made by Player A overturns the status quo then the reciprocal response, for Player Bs with preferences consistent with Axiom R, will be stronger than when the status quo is upheld. Therefore, a conservative test of the status quo effect focuses on individuals who demonstrated that they have strictly reciprocal preferences by selecting at least one decision to punish or reward another at a monetary cost to themselves. In other words, we exclude Player Bs who chose No change in both subgames from further analysis. Player B's behavior after such elimination is presented in the bottom panel of Table 1. Using data from Players B who demonstrated reciprocal preferences, Axiom $\mathrm{S}$ passes a strict test in each of the individual subgames ( $p=0.039$ and 0.032 , respectively for the left and right subgames).

\footnotetext{
${ }^{12}$ The data as presented in Tables 1 and 2 are not properly categorized for running Fisher's exact test, which requires probabilities across the four (independent) categories to sum to 1 . We present the categorization based on subjects' strategies in Appendix A.
} 


\subsection{Experiment 2: Randomly Assigned Endowments}

As argued above, the test of Axiom $S$ hinges on saliency of the status quo. In Experiment 1, we induced clear entitlements to the initial endowments by having subjects earn them by performance in the GMAT quiz. Experiment 2 addresses two issues. First, it allows us to test whether the procedures used to implement the status quo in Experiment 1 were the driving force behind the observed support for Axiom S. We do so by using procedures identical to Day 2 procedures of Experiment 1 with the only difference that we assign endowments to subjects randomly. In what follows we refer to Experiment 2 treatments as RANDOM $T_{15,5}$ and RANDOM $T_{10,10}$. From this perspective Experiment 2 is a robustness check for Axiom $\mathrm{S}$ with respect to weak entitlements, as they are often implemented in laboratory environments. ${ }^{13}$

\subsection{Experiment 2 Results}

Sixty-six subjects (or thirty-three pairs) participated in treatment RANDOM $T_{15,5}$ and sixty-eight subjects (or thirty-four pairs) in treatment RANDOM $T_{10,10}$. In treatment RANDOM $T_{15,5}$, twelve (=36.4\%) Player As chose to Uphold $(15,5)$ while twenty-one Player As chose to Give 5 to their counterpart Player B. In treatment RANDOM $T_{10,10}$, twenty-six $(=76.5 \%)$ chose to Take 5 while only eight chose to Uphold $(10,10)$. This difference in Player As' behavior is statistically significant $(p=0.001){ }^{14}$

Player Bs' behavior is presented in Table 2. Following the Uphold $(15,5)$ decision by Player A in treatment RANDOM $T_{15,5}$, only seven $(=21.2 \%)$ Player Bs punished Player A by Decreasing his payoff by 6, while the remaining twenty-six chose No

\footnotetext{
${ }^{13}$ Given the design of Experiment 1 in which the performance-based ranking of subjects determines the size of their endowment and thus also the role, one may wonder whether the observed change in behavior could be driven not by the treatment differences but by different subject characteristics as the subjects who scored higher in the GMAT quiz and earned higher endowments could have different reciprocal preferences from those who scored lower and earned lower endowments (see Ball, Eckel, Grossman, and Zame, 2001 for a related study). Although we could not think of any compelling link between mathematical ability and reciprocal behavior, Experiment 2 addresses this issue.

${ }^{14}$ Player A's behavior is summarized in Table 3 in Section 5.
} 
decrease. Following the Give 5 decision, twelve (=36.4\%) Player Bs rewarded Player A by choosing Increase by 2 , while the remaining twenty-one chose No increase.

Table 2: Player Bs' Behavior in Experiment 2

\begin{tabular}{|c|c|c|c|c|}
\hline & No Decrease & Decrease by 6 & No increase & Increase by 2 \\
\hline \multicolumn{5}{|c|}{ All Player Bs } \\
\hline RANDOM $T_{15,5}$ & $26 / 33(78.8 \%)$ & $7 / 33(21.2 \%)$ & $21 / 33(63.6 \%)$ & $12 / 33(36.4 \%)$ \\
\hline $\begin{array}{l}\text { Axiom S } \\
\text { Prediction }\end{array}$ & - & $<$ & - & $>$ \\
\hline RANDOM $T_{10,10}$ & $20 / 34(68.6 \%)$ & $14 / 34(41.4 \%)$ & $32 / 34(94.1 \%)$ & $2 / 34(5.9 \%)$ \\
\hline $\begin{array}{c}\text { Fisher's Test for } \\
\text { Strategies }\end{array}$ & \multicolumn{4}{|c|}{$0.000^{\mathrm{a}}$} \\
\hline $\begin{array}{c}\text { Fisher's Test for } \\
\text { Subgames }\end{array}$ & \multicolumn{2}{|c|}{0.067} & \multicolumn{2}{|c|}{0.002} \\
\hline \multicolumn{5}{|c|}{ Reciprocal Player Bs } \\
\hline RANDOM $T_{15,5}$ & $10 / 17(58.8 \%)$ & $7 / 17(41.2 \%)$ & $5 / 17(29.4 \%)$ & $12 / 17(70.6 \%)$ \\
\hline $\begin{array}{c}\text { Axiom S } \\
\text { Prediction }\end{array}$ & - & $<$ & - & $>$ \\
\hline RANDOM $T_{10,10}$ & $1 / 15(6.7 \%)$ & $14 / 15(93.3 \%)$ & $13 / 15(86.7 \%)$ & $2 / 15(13.3 \%)$ \\
\hline $\begin{array}{c}\text { Fisher's Test for } \\
\text { Subgames }\end{array}$ & \multicolumn{2}{|c|}{0.002} & \multicolumn{2}{|c|}{0.001} \\
\hline
\end{tabular}

${ }^{a}$ two-sided test.

Following the Take 5 decision by Player $\mathrm{A}$ in treatment RANDOM $T_{10,10}$, fourteen $(=41.1 \%)$ Player Bs punished Player A by Decreasing his payoff by 6 , while the remaining twenty chose No decrease. Following the Uphold $(10,10)$ decision by Player A, only two (=5.9\%) Player Bs rewarded Player A by Increasing his payoff by 2, while the remaining thirty-two chose No increase.

To assess the impact of earned endowments on Player B reciprocal responses, we compare their behavior in the respective treatments of Experiments 1 and 2 using all data categorized by strategies. We find no statistical differences between the EARNED $T_{15,5}$ and RANDOM $T_{15,5}$ treatments ( $\mathrm{p}=0.897$, two-sided Fisher's test). However, as can 
be seen from Table 4 presented in Appendix A, there were substantially more subjects who chose both to punish in the left subgame and reward in the right subgame in treatment RANDOM $T_{10,10}$ than in treatment EARNED $T_{10,10}$ (thirteen vs. two subjects, respectively), making the distribution of strategies significantly different across the two treatments $(\mathrm{p}=0.000$ two-sided Fisher's test). This highlights an interesting observation that subjects were more likely to play a "fully-reciprocal strategy," i.e., to punish for overturning the status quo and to reward for upholding it when the endowments were assigned randomly. ${ }^{15}$ However, the overall distribution of play between the two $T_{10,10}$ treatments was similar (see the third rows in Table 1 and Table 2). This suggests that a random assignment of endowments was sufficient to establish strong enough property rights and/or entitlements for the manifestation of Axiom S in subjects' reciprocal behavior.

We proceed to testing Axiom $\mathrm{S}$ with data from Experiment 2. Fisher's test for strategies rejects the null hypothesis in favor of the alternative ( $p=0.000$, two-sided), providing strong support for Axiom $\mathrm{S}$ in our data. Fisher's test for the subgame on the left side of the game tree implies that the frequency of Decrease by 6 is higher in RANDOM $T_{10,10}$ than in RANDOM $T_{15,5}(p=0.067)$. For the subgame on the right side, Fisher's test detects that the frequency of Increase by 2 is higher in RANDOM $T_{15,5}$ than RANDOM $T_{10,10}(p=0.002)$. After removing Player Bs who chose No change in both subgames, the test rejects the null with even higher confidence $(p=0.002$ and $p=0.001$, respectively, for the left and right subgames).

\section{The Effect of Earned Endowments on Player As' Behavior}

While the main focus of the current paper is on the reciprocal behavior of Player Bs, let us briefly discuss the effect of earned endowments on Player As' behavior. Unlike Player Bs, Player As show a great sensitivity to procedures under which the initial

\footnotetext{
${ }^{15}$ It is possible that such behavior is related to the issue of procedural fairness. However, since studying which experimental procedure makes subjects more reciprocal was not the main objective of our experiment, we leave it for future explorations. Recall that the main reason for having subjects earn their endowments in Experiment 1 was to create a salient status quo, which could have been necessary for eliciting responses that exhibit the implications of Axiom S.
} 
endowments were allocated. Table 3 summarizes and compares their behavior in the two experiments. Not only do we observe a significant difference in Player As' behavior between the two treatments in both experiments $\left(\mathrm{p}=0.065\right.$ for EARNED $T_{15,5}$ vs. EARNED $T_{10,10}$ and $\mathrm{p}=0.001$ for RANDOM $T_{15,5}$ vs. RANDOM $T_{10,10}$ ), but we also find a

Table 3. Comparison of Player A's Behavior

\begin{tabular}{|l|c|c|c|c|}
\hline & \multicolumn{2}{|c|}{$T_{15,5}$} & \multicolumn{2}{c|}{$T_{10,10}$} \\
\hline & Give 5 & Uphold (15,5) & Uphold (10,10) & Take 5 \\
\hline EARNED Endowments & $12 / 35(34.3 \%)$ & $23 / 35(65.7 \%)$ & $23 / 35(65.7 \%)$ & $12 / 35(34.3 \%)$ \\
\hline EARNED $T_{15,5}$ vs. EARNED $T_{10,10}$ & \multicolumn{4}{|c|}{$0.016^{\mathrm{a}}$} \\
\hline \multicolumn{5}{|l|}{$0.001^{\mathrm{a}}$} \\
\hline RANDOM Endowments & $21 / 33(63.6 \%)$ & $12 / 33(36.4 \%)$ & $8 / 34(23.5 \%)$ & $26 / 34(76.5 \%)$ \\
\hline RANDOM $T_{15,5}$ vs. RANDOM & \multicolumn{5}{|l|}{$0.028^{\mathrm{a}}$} \\
$T_{10,10}$ & \multicolumn{5}{|c|}{$0.001^{\mathrm{a}}$} \\
\hline \multicolumn{5}{|l|}{} \\
\hline EARNED $T_{15,5}$ vs. RANDOM $T_{15,5}$ & \multicolumn{5}{|l|}{} \\
\hline EARNED $T_{10,10}$ vs. RANDOM $T_{10,10}$ & \multicolumn{5}{|c|}{} \\
\hline
\end{tabular}

${ }^{a}$ two-sided Fisher's Test.

significant difference in frequencies of choosing to Give 5 between treatments EARNED $T_{15,5}$ and RANDOM $T_{15,5}(34.3 \%$ vs. $63.6 \%$, respectively; $p=0.028$, two-sided), providing evidence that Player As were less generous when they had to earn their endowments. Comparison of treatments EARNED $T_{10,10}$ and RANDOM $T_{10,10}$ reveals that the frequency of Take 5 is lower when the endowments are earned, than when they are assigned randomly ( $34.3 \%$ vs. $76.5 \%$, respectively; $p=0.001$, two-sided), pointing out that subjects honor property rights created by performance in the math quiz. 


\section{Discussion}

We have presented two experiments that discriminate between revealed altruism theory (Cox, Friedman, and Sadiraj, 2008) and alternative theories of social preferences. The design of our experiments is focused on the empirical validity of Axiom $S$, the component of revealed altruism theory that implies that (positively and negatively) reciprocal responses will be more pronounced when they are motivated by acts of commission than by acts of omission. We find clear evidence in both experiments in favor of Axiom $\mathrm{S}$ (status quo) and Axiom R (reciprocity) and against theories of unconditional social preferences in which willingness to pay to increase or decrease another person's material payoff is invariant to their actions.

The primary difference between the two experiments was the saliency of entitlements to endowments. Based on previous experimental evidence on earned endowments and behavior, we conjectured that earned endowments could be key to the empirical bite of Axiom $\mathrm{S}$ and the intensity of reciprocal reactions towards acts of commission. In everyday life the money in one's wallet is in most cases earned and regarded by the owner as being well deserved. People routinely exchange their time and effort for wages to which they form a strong sense of ownership or entitlement. In the laboratory, we cannot ask subjects to play with their own money and therefore strong entitlements are not easily established. In our Experiment 1 we approached this problem by splitting the experiment into two days and having subjects earn their endowments on Day 1 of the experiment. Not only did the subjects have to work for the endowments but they also had some time between the earning part and the game part to develop a sense of ownership of their earnings (Strahilevitz and Loewenstein, 1998). Earned endowments significantly affected giving and taking by first movers but to our surprise had insignificant effect on second movers' reciprocal responses as the behavior predicted by Axiom S was prevalent in both scenarios, highlighting the clear importance of the distinction between acts of commission and acts of omission (see also Blount, 1995; Charness, 2004).

Our results imply that subjects with reciprocal preferences are quite sensitive to acts of commission, i.e., acts that overturn the status quo. In our experiment we have developed a procedure that makes the status quo salient rather naturally. It involves a 
combination of initial endowments and framing of actions that make acts of commission, such as giving or taking, stand in stark contrast with acts of omission, such as not giving or not taking when there is an opportunity to do so.

One can ask whether this is all it takes to establish a status quo in general environments. Experience, habits, customs and norms are likely to play an important role in some contexts. From this perspective field experimentation might be another fruitful avenue for future research on the empirical significance of acts of commission vs. acts of omission. The field has the advantage that both the status quo and entitlements to endowments arise naturally. However, the complexity and richness of the field environment might stand in the way of clearly identifying and interpreting the status quo conditions for both researchers as well as participants.

Acknowledgements: Martin Dufwenberg, Daniel Friedman, and Robert Slonim provided helpful comments and suggestions. Financial support for this study was provided by the University of Canterbury, College of Business and Economics. The Erskine Programme supported this research with a Visiting Erskine Fellowship awarded to James C. Cox to visit the University of Canterbury; he subsequently received support from the National Science Foundation (grant number SES-0849590). 


\section{References}

Arkes, H.R.; Joyner, C.A.; Pezzo, M.V.; Nash, J.G.; Siegel-Jacobs, K.; Stone, E. The Psychology of Windfall Gains. Organizational Behavior and Human Decision Processes 1994, 59, 331-347.

Ball, S., C.C. Eckel, P.J. Grossman, W. Zame "Status in Markets." Quarterly Journal of Economics 2001, 116(1): 161-181.

Baron, J. and I. Ritov, I. Reference points and omission bias. Organizational Behavior and Human Decision Processes 1994, 59, 475-498.

Battalio, R.C.; Kagel, J.H.; Jiranyakul, K. Testing Between Alternative Models of Choice Under Uncertainty: Some Initial Results. Journal of Risk Uncertainty 1990, 3, 25-50.

Bennett, J. (1983). Positive and negative relevance. American Philosophical Quarterly, 20, 183-194.

Bennett, J. (1966). Whatever the consequences. Analysis, 26, 83-102 (reprinted in B. Steinbock, ed., Killing and letting die, 109-127. Englewood Cliffs, NJ: Prentice Hall). Bennett, J. (1981). Morality and consequences. In S. M. McMurrin (Ed.), The Tanner Lectures on human values (vol. 2, 45-116). Salt Lake City: University of Utah Press.

Berg, J.; Dickhaut, J.; McCabe, K. Trust, Reciprocity, and Social History. Games and Economic Behavior 1995, 10, 122-142.

Blount, S. When social outcomes aren't fair: the effect of causal attributions on preferences. Organizational Behavior and Human Decision Processes 1995, 63, 131144.

Bolton, G.E.; Ockenfels, A. ERC: A Theory of Equity, Reciprocity, and Competition. American Economic Review 2000, 90, 166-193.

Brandts, J.; Charness, G. The Strategy versus the Direct-response Method: A Survey of Experimental Comparisons. Experimental Economics 2011, 14(3), 375-398.

Charness, G. "Attribution and Reciprocity in an Experimental Labor Market," Journal of Labor Economics 2004, 22, 665-688.

Charness, G.; Rabin, M. Understanding Social Preferences with Simple Tests. Quarterly Journal of Economics 2002, 117, 817-869.

Cherry, T.; Frykblom, P.; Shogren, J. Hardnose the Dictator. American Economic Review 2002, 92, 1218-1221. 
Clark, J. House Money Effects in Public Good Experiments. Experimental Economics 2002, 5, 223-231.

Cox, J.C. How to Identify Trust and Reciprocity. Games and Economic Behavior 2004, 46, 260-281.

Cox, J. C.; Friedman, D.; Gjerstad, S. A Tractable Model of Reciprocity and Fairness. Games and Economic Behavior 2007, 59, 17-45.

Cox, J.C.; Friedman, D.; Sadiraj, V. Revealed Altruism. Econometrica 2008, 76, 31-69.

Cox , J.C. and Hall, D. Trust with Private and Common Property: Effects of Stronger Property Right Entitlements. Games 2010, 1, 1-24.

Cox, J.C.; Ostrom, E.; Walker, J.M.; Castillo, J.; Coleman, E.; Holahan, R.; Schoon, M.; Steed, B. Trust in Private and Common Property Experiments. Southern Economic Journal 2009, 75, 957-975.

Cox, J.C.; Sadiraj, V. On Modeling Voluntary Contributions to Public Goods. Public Finance Review 2007, 35, 311-332.

Dufwenberg, M. and G. Kirchsteiger, A Theory of Sequential Reciprocity. Games and Economic Behavior, 47, 2004, 268-98.

Falk, A. and U. Fischbacher. A Theory of Reciprocity. Games and Economic Behavior 54, 2006, 293-315.

Fehr, E.; Schmidt, K.M. A Theory of Fairness, Competition, and Cooperation. Quarterly Journal of Economics 1999, 114, 817-868.

Foot, P. The Problem of Abortion and the Doctrine of the Double Effect in Virtues and Vices (Oxford: Basil Blackwell, 1978)

Hare, R. M. (1981). Moral thinking: Its levels, method and point. Oxford: Oxford University Press (Clarendon Press)

Gächter, S.; Riedl, A. Moral Property Rights in Bargaining with Infeasible Claims. Management Science 1995 51, 249-263.

Greene, J.D. Why are VMPFC Patients More Utilitarian?: A Dual-Process Theory of Moral Judgment Explains. Trends in Cognitive Sciences 2007. 11(8), 322-323.

Harrison, G.W. House Money Effects in Public Goods Experiments: Comment. Experimental Economics 2007, 10, 429-437. 
Hoffman, E., K. McCabe, K. Shachat, and V. Smith. Preferences, Property Rights, and Anonymity in Bargaining Games. Games and Economic Behavior 1994, 7(3), 346-80.

Kagan, S. (1988). The additive fallacy. Ethics, 99, 5-31.

Kahneman, D., and Tversky, A. The psychology of preferences. Scientific American 1982, 246, 160-173.

Kamm, F. M. Harming, not aiding, and positive rights. Philosophy and Public Affairs 1986, 15, 3-32.

Kamm, F. M. Harming Some to Save Others, Philosophical Studies 1989, 57, 227-60.

Keasey, K.; Moon, P. Gambling with the House Money in Capital Expenditure Decisions: An Experimental Analysis. Economics Letters 1996, 50, 105-110.

Kahneman, D., J.L. Knetsch, and R.Thaler. Experimental Test of the Endowment Effect and the Coase Theorem. Journal of Political Economy 1990, 98(6).

Kahneman, D., and A. Tversky. Prospect Theory: An Analysis of Decision under Risk. Econometrica, 1979, 47(2), 263-291.

Moll, J. and de Oliveira-Souza, R. Moral Judgments, Emotions, and the Utilitarian Brain. Trends in Cognitive Sciences 2007, 11, 319-321.

Ritov, I. and J. Baron. Status-quo and omission bias. Journal of Risk and Uncertainty 1992, 5, 49-61.

Rutström, E. and M. Williams. Entitlements and Fairness: An Experimental Study of Distributive Preferences. Journal of Economic Behavior and Organization 2000, 43(1), 75-89.

Samuelson, W., and Zeckhauser, R. (1988). Status quo bias in decision making. Journal of Risk and Uncertainty, 1, 7-59.

Rutström, E. and M. Williams. Entitlements and Fairness: An Experimental Study of Distributive Preferences. Journal of Economic Behavior and Organization 2000, 43(1), 75-89.

Schlueter, L.L. Punitive Damages. $5^{\text {th }}$ ed., vol. 1, Matthew Bender \& Co, Inc., Lexis Nexis Group, 2005.

Selten, R. Die Strategiemethode zur Erforschung des eingeschränkt rationale Verhaltens im Rahmen eines Oligopolexperiments," in H. Sauermann (ed.), Beiträge zur experimentellen Wirtschaftsforschung, Tübingen: Mohr, 136-168. 1967

Singer, P. (1979). Practical ethics. Cambridge University Press. 
Spranca, M., E. Minsk, E., and J. Baron. Omission and commission in judgment and choice. Journal of Experimental Social Psychology 1991, 27, 76-105.

Steinbock, B. (Ed.) (1980). Killing and letting die. Englewood Cliffs, NJ: Prentice Hall. Strahilevitz, M., and Loewenstein, G. The effect of ownership history on the valuation of objects. Journal of Consumer Research 1998, 25, 276-289.

Thaler, R.H. Anomalies: Saving, Fungibility, and Mental Accounts. Journal of Economic Perspectives 1990, 4, 193-205.

Thaler, R.H.; Johnson, E.J. Gambling with the House Money and Trying to Break Even: The Effects of Prior Outcomes on Risky Choice. Management Science 1990, 36, 643660.

Thomson, J. The trolley problem. Yale Law Journal 1985, 94, 1395-1415. 
Appendix A: Raw Data on Player Bs' Behavior Categorized According to Strategies

Table 4.

\begin{tabular}{|l|c|c|c|c|}
\hline & \multicolumn{4}{|c|}{ Strategies } \\
\hline Treatment & ND-NI & ND-IB2 & DB6-NI & DB6-IB2 \\
\hline EARNED $T_{15,5}$ & 14 & 13 & 5 & 2 \\
\hline EARNED $T_{10,10}$ & 20 & 4 & 9 & 2 \\
$\mathrm{n}=35$ & 16 & 10 & 5 & 13 \\
\hline RANDOM $T_{15,5}$ & 19 & 1 & 1 & \\
$\mathrm{n}=33$ & & & & \\
\hline RANDOM $T_{10,10}$ & \multirow{2}{*}{10} & & & \\
$\mathrm{n}=34$ & & & & \\
\hline
\end{tabular}

$$
\begin{aligned}
& \mathrm{ND}=\text { No Decrease } \\
& \text { DB6 = Decrease by } 6 \\
& \mathrm{NI}=\text { No Increase } \\
& \text { IB2 }=\text { Increase by } 2
\end{aligned}
$$




\section{Appendix B: Subject Instructions and Decision Forms (Experiment 1)}

\section{DAY 1}

\section{INSTRUCTIONS}

\section{Earnings quiz}

In today's part of the experiment you will be asked to complete a quiz. Each participant will be asked to answer the same set of 40 questions, selected from a large test bank. Your quiz score will be the number of questions you answer correctly minus 1/4 of a point for each question that you answer incorrectly (i.e., 1 correct answer $=1$ point; 1 incorrect answer $=-1 / 4$ point $)$.

After everyone has completed the experiment the final scores will be ranked from the highest to the lowest and ties will be resolved randomly. Once the complete ranking of the participants has been determined, the participants who scored in the top $25 \%$ will receive a certificate for $\$ 15$, those in the middle $25-75 \%$ will receive a certificate for $\$ 10$, and those in the bottom $25 \%$ will receive a certificate for $\$ 5$.

IMPORTANT: Please bring your certificates to the DAY 2 part of the experiment. They provide your start up money for the second part of the experiment. At the end of the DAY 2 session your experimental earnings will be converted into cash at the 3:4 exchange rate (i.e., each $\$ 0.75$ of your experimental earnings will be worth 1 NZD in cash).

Please mark your answer in the quiz by clicking inside the dialog box to the left of the option you want to select. You have 40 minutes to complete the quiz. 


\section{DAY 2}

\section{No Talking Allowed}

\section{INSTRUCTIONS \\ (Status Quo Treatment 15-5)}

Now that the experiment has begun, we ask that you do not talk. If you have a question after we finish reading the instructions, please raise your hand and the experimenter will approach you and answer your question in private.

\section{Show up Fee}

Every participant will get 5 NZD as a show up fee for today's session and, in addition, have the opportunity to earn money in the experiment. Your experimental earnings (in \$) will be converted into cash at the 3:4 exchange rate (i.e., each $\$ 0.75$ of your experimental earnings will be worth 1 NZD.) All the money will be paid to you in cash at the end of the experiment.

\section{Two Groups}

You have been divided into two groups, called Players A and Players B. Participants who scored in the top 25\% in the quiz on DAY 1 will be Players A and participants who scored in the bottom $25 \%$ will be Players B.

\section{Anonymity}

Each Player A will be randomly paired with a Player B. No one will learn the identity of the player (s)he is paired with.

\section{Complete Privacy}

This experiment is structured so that no one, neither the experimenters nor the other participants nor anyone else will ever know the personal decision of anyone in the experiment. This is accomplished by the following procedure. You will collect your money payoff, contained in a sealed envelope, from our research assistant in exchange for your experiment ID slip. Your privacy is guaranteed because neither your name nor your student ID number will appear on any form that records your decisions in this experiment. The only identifying mark in all records will be the experiment ID which is known only by you. Although the experimenters will not know your identity, they will know how much to pay you because you will write your experiment ID number on all response forms.

At the end of the experiment, each subject will walk by himself or herself to another room to collect their money payoff envelope from our research assistant who will not be present during the decision making part of the experiment. You will be the only person in possession of your experiment ID slip. When collecting the envelope, you are kindly requested not to open it immediately. You should wait until you leave the building. After collecting the envelope, you must return your experiment ID slip to our research assistant

\section{Starting Money Balances}

Your starting balances for this DAY 2 part of the experiment were determined by your performance on DAY 1 of this experiment:

Each Player A earned \$15 on DAY 1 by scoring in the top 25\% on the quiz. Each Player B earned \$5 on DAY 1 by scoring in the bottom $25 \%$ on the quiz. 


\section{Player A's Decision Task}

- Each Player A decides whether or not to give $\$ 5$ to the paired Player B.

- If Player A decides to give $\$ 5$ to the paired Player B, (s)he makes his/her decision by circling the "Player A has decided to give $\mathbf{\$ 5}$ to Player B" statement on the decision form. If Player A decides not to give $\$ 5$ to the paired Player B, (s)he makes his/her decision by circling the "Player A has decided to make no change in payoffs" statement.

Player A is asked to circle only one of the two decisions. If Player A does not circle a decision or circles both decisions, (s)he will be paid only the show-up fee at the end of the experiment. After making his/her decision, Player A places the decision form in the manila envelope and waits for the experimenter to collect it.

\section{Player B's Decision Task}

Each Player B makes a decision for both of the two possible Player A decisions:

- If Player A has decided to make no change in payoffs, Player B chooses between:

Decision N1: Make no further change in payoffs

OR

Decision N2: Decrease his/her own payoff by $\$ 2$ in order to decrease player A's payoff by $\$ 6$

- If Player A has decided to give $\mathbf{\$ 5}$ to Player B, Player B chooses between:

Decision G1: Make no further change in payoffs

OR

Decision G2: Decrease his/her own payoff by $\$ 1$ in order to increase player A's payoff by $\$ 2$

Player B makes his/her decisions by circling one of the two possible decisions on each of the two decision forms. Player B is asked to circle only one of the two possible decisions on each of the two decision forms. If Player B does not circle any decision or circles both decisions on the same decision form, (s)he will be paid only the show-up fee at the end of the experiment. After making his/her decisions, Player B puts both decision forms in the large manila envelope and waits for the experimenter to collect it.

Note that Player A's decision will determine which decision of Player B will be relevant. However, Players B will not know in advance which one will be chosen. Therefore, please think about your decisions carefully. Are there any questions? 
DECISION FORM FOR PLAYER A (Treatment 15/5)

Experiment ID of Player A:

Player A starts with $\$ 15$ he/she earned on DAY 1. Player B starts with $\$ 5$ he/she earned on DAY 1.

\section{DECISION (1): Player A decides to make no change in payoffs}

Subsequently, Player B will decide to:

Make no further change in payoffs

OR

Decrease his/her own payoff by $\$ 2$ in order to decrease player A's payoff by $\$ 6$

\section{OR}

\section{DECISION (2): Player A decides to give \$5 to Player B}

Subsequently, Player B will decide to:

Make no further change in payoffs

OR

Decrease his/her own payoff by $\$ 1$ in order to increase player A's payoff by $\$ 2$

YOU MUST CIRCLE EITHER DECISION (1) OR DECISION (2) BUT NOT BOTH. 
DECISION FORM FOR PLAYER B (Treatment 15/5, page 1)

Experiment ID of Player B:

Player A starts with $\$ 15$ he/she earned on DAY 1. Player B starts with $\$ 5$ he/she earned on DAY 1.

\section{IF Player A has decided to make no change in payoffs THEN}

Player B chooses between:

Decision N1: Make no further change in payoffs

OR

Decision N2: Decrease his/her own payoff by $\$ 2$ in order to decrease player A's payoff by $\$ 6$

YOU MUST CIRCLE EITHER DECISION N1 OR DECISION N2 BUT NOT BOTH. 
DECISION FORM FOR PLAYER B (Treatment 15/5, page 2)

Experiment ID of Player B:

Player A starts with $\$ 15$ he/she earned on DAY 1. Player B starts with $\$ 5$ he/she earned on DAY 1.

\section{IF Player A has decided to give \$5 to Player B THEN}

Player B chooses between:

Decision G1: Make no further change in payoffs

OR

Decision G2: Decrease his/her own payoff by $\$ 1$ in order to increase player A's payoff by $\$ 2$

YOU MUST CIRCLE EITHER DECISION G1 OR DECISION G2 BUT NOT BOTH. 


\section{DAY 2}

No Talking Allowed

INSTRUCTIONS

(Status Quo Treatment 10-10)

Now that the experiment has begun, we ask that you do not talk. If you have a question after we finish reading the instructions, please raise your hand and the experimenter will approach you and answer your question in private.

\section{Show up Fee}

Every participant will get 5 NZD as a show up fee for today's session and, in addition, have the opportunity to earn money in the experiment. Your experimental earnings (in \$) will be converted into cash at the 3:4 exchange rate (i.e., each $\$ 0.75$ of your experimental earnings will be worth 1 NZD.) All the money will be paid to you in cash at the end of the experiment.

\section{Two Groups}

You have been divided randomly into two groups, called Players A and Players B.

\section{Anonymity}

Each Player A will be randomly paired with a Player B. No one will learn the identity of the player (s)he is paired with.

\section{Complete Privacy}

This experiment is structured so that no one, neither the experimenters nor the other participants nor anyone else will ever know the personal decision of anyone in the experiment. This is accomplished by the following procedure. You will collect your money payoff, contained in a sealed envelope, from our research assistant in exchange for your experiment ID slip. Your privacy is guaranteed because neither your name nor your student ID number will appear on any form that records your decisions in this experiment. The only identifying mark in all records will be the experiment ID which is known only by you. Although the experimenters will not know your identity, they will know how much to pay you because you will write your experiment ID number on all response forms.

At the end of the experiment, each subject will walk by himself or herself to another room to collect their money payoff envelope from our research assistant who will not be present during the decision making part of the experiment. You will be the only person in possession of your experiment ID slip. When collecting the envelope, you are kindly requested not to open it immediately; you should wait until you leave the building. After collecting the envelope, you must return your experiment ID slip to our research assistant

\section{Starting Money Balances}

Your starting balances for this DAY 2 part of the experiment were determined by your performance on DAY 1 of this experiment:

Each Player A earned \$10 on DAY 1 by scoring in the middle $25-75 \%$ on the quiz. Each Player B earned \$10 on DAY 1 by scoring in the middle $25-75 \%$ on the quiz. 


\section{Player A's Decision Task}

- Each Player A decides whether or not to take $\$ 5$ from the paired Player B.

- If Player A decides to take $\$ 5$ from the paired Player B, (s)he makes his/her decision by circling the "Player A has decided to take \$5 from Player B" statement on the decision form. If Player A decides not to take $\$ 5$ from the paired Player B, (s)he makes his/her decision by circling the "Player A has decided to make no change in payoffs" statement.

Player A is asked to circle only one of the two decisions. If Player A does not circle a decision or circles both decisions, (s)he will be paid only the show-up fee at the end of the experiment. After making his/her decision, Player A places the decision form in the manila envelope and waits for the experimenter to collect it.

\section{Player B's Decision Task}

Each Player B makes a decision for both of the two possible Player A decisions:

- If Player A has decided to take $\$ \mathbf{5}$ from Player B, Player B chooses between:

Decision T1: Make no further change in payoffs

OR

Decision T2: Decrease his/her own payoff by $\$ 2$ in order to decrease player A's payoff by $\$ 6$

- If Player A has decided to make no change in payoffs, Player B chooses between:

Decision N1: Make no further change in payoffs

OR

Decision N2: Decrease his/her own payoff by $\$ 1$ in order to increase player A's payoff by $\$ 2$

Player B makes his/her decisions by circling one of the two possible decisions on each of the two decision forms. Player B is asked to circle only one of the two possible decisions on each of the two decision forms. If Player B does not circle any decision or circles both decisions on the same decision form, (s)he will be paid only the show-up fee at the end of the experiment. After making his/her decisions, Player B puts both decision forms in the large manila envelope and waits for the experimenter to collect it.

Note that Player A's decision will determine which decision of Player B will be relevant. However, Player B will not know in advance which one will be chosen. Therefore, please think about your all of decisions carefully. Are there any questions? 
DECISION FORM FOR PLAYER A (Treatment 10/10)

Experiment ID of Player A:

Player A starts with $\$ 10$ he/she earned on DAY 1. Player B starts with $\$ 10$ he/she earned on DAY 1.

\section{DECISION (1): Player A decides to take \$5 from Player B}

Subsequently, Player B will decide to:

Make no further change in payoffs

OR

Decrease his/her own payoff by $\$ 2$ in order to decrease player A's payoff by $\$ 6$

\section{OR}

\section{DECISION (2): Player A decides to make no change in payoffs}

Subsequently, Player B will decide to:

Make no further change in payoffs

OR

Decrease his/her own payoff by $\$ 1$ in order to increase player A's payoff by $\$ 2$

YOU MUST CIRCLE EITHER DECISION (1) OR DECISION (2) BUT NOT BOTH. 
DECISION FORM FOR PLAYER B (Treatment 10/10, page 1)

Experiment ID of Player B:

Player A starts with $\$ 10$ he/she earned on DAY 1. Player B starts with $\$ 10$ he/she earned on DAY 1.

\section{IF Player A has decided to take \$5 from Player B THEN}

Player B chooses between:

Decision T1: Make no further change in payoffs

OR

Decision T2: Decrease his/her own payoff by $\$ 2$ in order to decrease player A's payoff by $\$ 6$

YOU MUST CIRCLE EITHER DECISION T1 OR DECISION T2 BUT NOT BOTH. 
DECISION FORM FOR PLAYER B (Treatment 10/10, page 2)

Experiment ID of Player B:

Player A starts with $\$ 10$ he/she earned on DAY 1. Player B starts with $\$ 10$ he/she earned on DAY 1.

\section{IF Player A has decided to make no change in payoffs THEN}

Player B chooses between:

Decision N1: Make no further change in payoffs

OR

Decision N2: Decrease his/her own payoff by $\$ 1$ in order to increase player A's payoff by $\$ 2$

YOU MUST CIRCLE EITHER DECISION N1 OR DECISION N2 BUT NOT BOTH. 


\section{Appendix C: IOU Certificate}

August 1, 2010

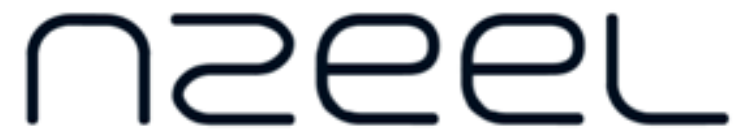

New Zealand Experimental Economics Laboratory

\section{\$15 IOU CERTIFICATE}

Payable to:

IMPORTANT: Please bring your IOU certificate to the DAY 2 part of the experiment. It provides your start up money for the second part of the experiment. At the end of the DAY 2 session your experimental earnings will be converted into cash at the 3:4 exchange rate (i.e., each $\$ 0.75$ of your experimental earnings will be worth 1 NZD in cash).

Signed by the experimenter: 


\section{Appendix D: Discussion of a Heuristic Application of Prospect Theory}

It has been argued that cumulative prospect theory (Tversky and Kahneman, 1992) implies that the $T_{15,5}$ and $T_{10,10}$ treatments are not isomorphic because of loss aversion relative to the endowments as reference points. Here is a critical examination of this type of heuristic application of prospect theory. Recall that prospect theory models self-regarding ("selfish") preferences on a lottery space. Suppose one views the second mover's payoff at a terminal node as a degenerate lottery. Also suppose that the second mover's payoff at any terminal node is coded as the difference between the money payoff at the node and his endowed payoff (a reference point). Then the value function $\mathrm{v}(\cdot)$ gives utilities for the payoffs at the four terminal nodes in the $T_{15,5}$ treatment as (from left to right in Figure 1.a): v(5-5), v(3-5), v(10-5), and v(9-5). Similarly, the value function evaluates payoffs at the four terminal nodes in the $T_{10,10}$ treatment as (from left to right in Figure 1.b): v(5-10), v(3-10), v(10-10), and v(9-10). These values (or utilities) imply the same choices as does the "economic man" model of choice on a commodity space: choose $(15,5)$ on the left branch and $(10,10)$ on the right branch in both games. In this way, a discussant's suggested heuristic application of prospect theory actually implies that the $T_{15,5}$ and $T_{10,10}$ treatments are isomorphic, not the opposite. 